\title{
INFLUENCE OF VARIOUS PARAMETERS ON THE DEFLUORINATION OF WET-PROCESS PHOSPHORIC ACID
}

\author{
G. Shaimerdenova ${ }^{\bowtie}$, K. Zhantasov, A. Kadirbayeva, G. Shaimerdenova, \\ G. Jussupbekova, Zh. Iztayev and B. Tastanbekova \\ M.Auezov South Kazakhstan University, 160012, Shymkent, Republic of Kazakhstan \\ ${ }^{\circledR}$ Corresponding Author: danel01kz@gmail.com
}

\begin{abstract}
One of the important sources of raw materials for the production of mineral fertilizers in wet-process phosphoric acid (WPA). It is known that WPA is obtained by treating natural raw materials directly with sulfuric acid. Since WPA is used in the production of mineral fertilizers, it is necessary to solve environmental problems with the rational and comprehensive use of mineral raw materials. This is because, during the extraction of natural raw materials, all impurities contained in phosphate raw materials are transferred to the composition of WPA. Therefore, the main goal is to clean the WPA from impurities.

This article discusses the purification of WPA from the fluoride deposition method with the use of inorganic reagents. As the inorganic reagent for defluorination WPA used sodium salt. The influence of temperature, time and norm of sodium salt on the deposition method is studied. As a result, the optimal parameters of the purification of WPA by precipitation were determined: the norm of sodium salt - $140 \%$ of stoichiometry; temperature $-40-50{ }^{\circ} \mathrm{C}$; time $-30 \mathrm{~min}$. Under these conditions, the degree of purification of WPA from fluorine is $84 \%$. The size of the crystals formed during the deposition of sodium silicofluoride is 40-50 microns. Composition of the purified WPA under these conditions (wt. \%): $\mathrm{P}_{2} \mathrm{O}_{5}-19 ; \mathrm{F}-0.24$.
\end{abstract}

Keywords: Wet-process, Phosphoric Acid, Defluorination, Cleaning Acid, Sodium Silicofluoride, Deposition of Impurities, Dry Sodium Salt.

RASĀYANJ. Chem., Vol. 14, No.4, 2021

\section{INTRODUCTION}

Kazakhstan is one of the largest regions of the world, which has significant reserves of mineral raw materials and prospects for expanding their use in various branches of the chemical industry. Thanks to the continuous operation of the "atmosphere - hydrosphere - soil - plants - animals" system, a biochemical cycle of many chemical elements and their compounds have developed, covering the earth, the atmosphere and the water basin. ${ }^{1}$ Technological progress constantly increases the possibilities of environmental impact, creates prerequisites for the emergence of environmental crises and disruption of the ecological balance. At the same time, the possibilities of eliminating the environmental degradation caused by human production activities are expanding. With the rational and comprehensive use of mineral resources, it is necessary to solve environmental problems. One of these problems at this stage is the processing of phosphorite into valuable products by chemical or thermal methods. One of the promising directions of chemical processing of phosphorite is its decomposition with sulfuric acid by dihydrate method to obtain phosphoric acid. Extraction decomposition of phosphorite with sulfuric acid proceeds with the formation of phosphogypsum and with fluorine released into the gas phase in the form of HF and $\mathrm{SiF}_{4}$, which are processed into $\mathrm{H}_{2} \mathrm{SiF}_{6}$. Work-related to the development of new methods that allow the processing of phosphate raw materials or waste from phosphorus production containing a significant amount of the valuable component $\mathrm{P}_{2} \mathrm{O}_{5}$ of wet-process phosphoric acid(WPA) is relevant.

WPA obtained from phosphorites of the Karatau basin contains several impurities, the main of which are compounds of iron, aluminum, magnesium, calcium, sodium, potassium, silicon, sulfur and fluorine. ${ }^{1}$ Depending on the direction of use of the acid and the type of raw material, siliceous-phosphate is determined from which of these impurities and how it should be purified. ${ }^{2,3}$

The most harmful impurity that limits the application of wet-process phosphoric acid is fluorine, which is found in acid, as has been described in the form of fluorides and silicofluorides. At the same time,

Rasayan J. Chem., 14(4), 2273-2278(2021)

http://doi.org/10.31788/RJC.2021.1446472

This work is licensed under a CC BY 4.0 license. 
RASĀYAN J. Chem.

Vol. 14 | No. 4 |2273-2278| October- December | 2021

fluorine and fluoride compounds are increasingly used in various sectors of the economy every year. ${ }^{1,3}$ Therefore, the issues of purification of WPA from fluorine and other impurities such as polymer iron oxide, aluminum, magnesium oxide and sulfur( $\mathrm{Al}, \mathrm{Fe}$ and $\left.\mathrm{SO}_{4}{ }^{2-}\right)$ are relevant.

For this purpose, studies have been carried out to investigate the deposition of fluorine from the acid of repetition by dry sodium salts, aqueous solutions of sodium salts and phosphoric acid solutions of sodium salts.

It is well known that the negative impact of fluoride on the plant and animal world causes irreparable damage. It is either washed away by the waters and gets into rivers, lakes, and then gets into drinking water. A significant amount of fluoride in plants inhibits photosynthesis ${ }^{4}$, destroys enzymes and reduces their activity. By ingestion of fluoride in the stomach of animals and humans impaired activity of the enzyme systems of the body, leads to softened and bone disease, impaired liver, kidney, heart, endocrine glands, disrupts the function of the central nervous system, etc. ${ }^{5}$

There are known methods for extracting fluorine from WPA by evaporation ${ }^{4,5}$ by precipitation of slightly soluble sodium and potassium salts ${ }^{2,4}$, as well as by sorption method. ${ }^{1,5}$

\section{EXPERIMENTAL}

Many authors believe that the best method of purification of WPA from fluorine is its precipitation in the form of silicofluoride compounds. ${ }^{6}$

To obtain WPA, off-balance ore phosphorites formed during production at the Zhanatas Deposit in the Karatau phosphorite basin are used as starting materials. They are classified as off-balance sheetsbecause the content of the main component of $\mathrm{P}_{2} \mathrm{O}_{5}$ is less than $18 \% .{ }^{1,7}$

For example, in the chemical method of obtaining WPA from phosphorites and apatites, the $\mathrm{P}_{2} \mathrm{O}_{5}$ content of the raw material should not be less than $24.5 \%$. Obtained by the dihydrate method, at temperatures of $90-95^{\circ} \mathrm{C}$ in extractors, phosphoric acid from phosphorites and apatites in the presence of sulfuric acid with concentrations of about $60 \%$ and harmful impurities such as oxides, calcium, magnesium, sulfur, one-and-a-half oxides, iron, aluminum and which reduce the quality of the acid fluoride, also has a negative impact on the surrounding fauna, flora and human health.Therefore, its cleaning and disposal are of paramount importance. ${ }^{4,6}$ Sulfuric acid is produced from natural sulfur-containing ore, mainly from pyrite, and currently from feed sulfur formed by oil production. ${ }^{4,11}$

In our opinion, the most promising method is the precipitation method and the method of fluorine released into the gas phase by heating or evaporating the acid. For this purpose, to precipitate fluorine as $\mathrm{Na}_{2} \mathrm{SiF}_{6}$ from acid. WPA is quite suitable for the production of ammophos. ${ }^{5,6}$ The presence of sodium ions in the acid does not significantly affect the processes of neutralization of phosphoric acid with ammonia, evaporation of neutralized pulp, granulation and drying of ammophos.

Precipitation of sodium silicofluoride from WPA with aqueous solutions of sodium salts in terms of $\mathrm{Na}_{2} \mathrm{O}$ was carried out depending on the no norm of the precipitator, the concentration of the solution, the temperature and the time of the process. ${ }^{8}$ The degree of defluorination, the size of $\mathrm{Na}_{2} \mathrm{SiF}_{6}$ crystals, and the content of $\mathrm{Na}_{2} \mathrm{O}, \mathrm{K}_{2} \mathrm{O}$, and $\mathrm{P}_{2} \mathrm{O}_{5}$ in the acid were determined. ${ }^{4,8}$

\section{RESULTS AND DISCUSSION}

The effect of temperature and time of the process on acid defluorination was studied in the temperature range of $25-70^{\circ} \mathrm{C}$ at a precipitation rate of $140 \%$ more than stoichiometryand a concentration of sodium salts in the form of $6.75 \% \mathrm{Na}_{2} \mathrm{O}$ (Table- 1 ).

Table-1: Effect of Temperature and Time of Process for Defluorination of Acid

\begin{tabular}{c|c|c|c|c|c|c}
\hline \multirow{2}{*}{$\mathrm{T},{ }^{0} \mathrm{C}$} & \multirow{2}{*}{$\begin{array}{c}\tau, \\
\mathrm{min}\end{array}$} & \multicolumn{3}{|c|}{ Content in WPA, \% } & Defluorination & Average Crystal \\
\cline { 3 - 5 } & $\mathrm{Na}_{2} \mathrm{O}$ & $\mathrm{K}_{2} \mathrm{O}$ & $\mathrm{F}$ & Degree, \% & Size, microns \\
\hline 25 & 10 & 0.539 & 0.198 & 0.25 & 84.22 & 21.8 \\
25 & 30 & 0.604 & 0.205 & 0.255 & 83.02 & 50.8 \\
25 & 45 & 0.607 & 0.181 & 0.268 & 82.41 & 32.4 \\
25 & 60 & 0.512 & 0.157 & 0.253 & 83.92 & 34.6 \\
\hline 40 & 10 & 0.607 & 0.181 & 0.282 & 81.71 & 39.2 \\
\hline
\end{tabular}


RASĀYAN J. Chem.

Vol. 14 | No. 4 |2273-2278| October- December | 2021

\begin{tabular}{l|l|c|c|c|c|c}
\hline 40 & 30 & 0.604 & 0.241 & 0.288 & 81.62 & 54.2 \\
40 & 45 & 0.608 & 0.193 & 0.30 & 81.54 & 48.0 \\
40 & 60 & 0.610 & 0.169 & 0.32 & 80.85 & 34.8 \\
\hline 50 & 10 & 0.600 & 0.181 & 0.325 & 80.32 & 46.0 \\
50 & 30 & 0.604 & 0.217 & 0.338 & 78.93 & 53.6 \\
50 & 45 & 0.610 & 0.193 & 0.343 & 78.32 & 34.6 \\
50 & 60 & 0.613 & 0.169 & 0.332 & 80.22 & 33.0 \\
\hline 60 & 10 & 0.604 & 0.145 & 0.348 & 77.54 & 28.4 \\
60 & 30 & 0.609 & 0.169 & 0.367 & 77.63 & 36.6 \\
60 & 45 & 0.619 & 0.181 & 0.37 & 77.35 & 34.6 \\
60 & 60 & 0.620 & 0.145 & 0.378 & 77.02 & 32.4 \\
\hline 70 & 10 & 0.604 & 0.169 & 0.388 & 74.56 & 24.8 \\
70 & 30 & 0.614 & 0.169 & 0.40 & 74.53 & 26.6 \\
70 & 45 & 0.615 & 0.241 & 0.35 & 74.42 & 24.0 \\
70 & 60 & 0.618 & 0.193 & 0.396 & 74.34 & 20.0 \\
\hline
\end{tabular}

The data of the obtained experiments show that an increase in temperature from 25 to $70^{\circ} \mathrm{C}$ during the same time leads to an increase in the solubility of sodium silicofluorides and, consequently, to an increase in the residual concentration of $\mathrm{F}$ in the acid and, consequently, to a decrease in the degree of defluorination. The largest crystals of $\mathrm{Na}_{2} \mathrm{SiF}_{6}$ fall out at 40 and $50^{\circ} \mathrm{C}$.

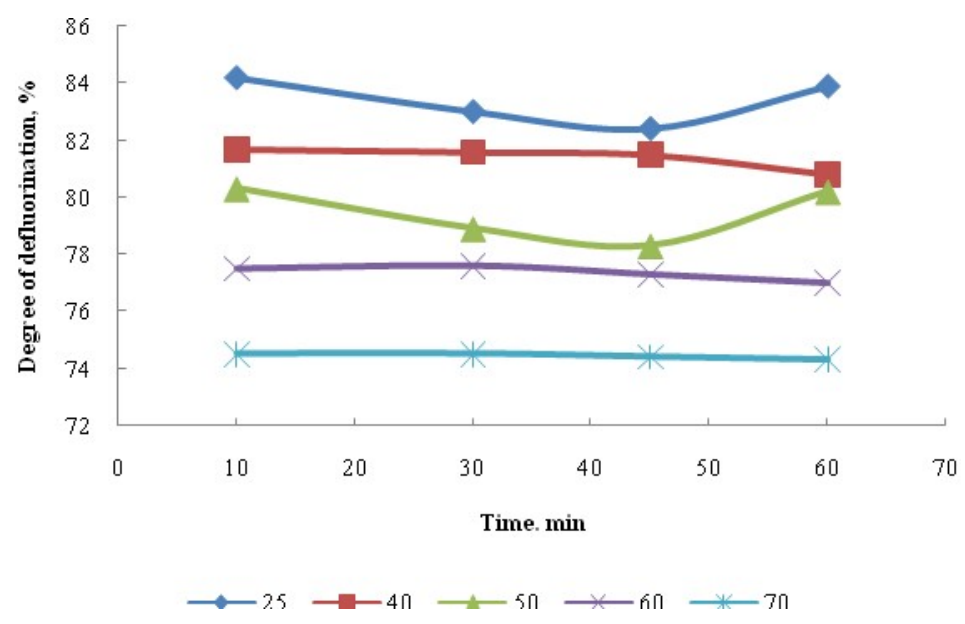

Fig.-1: Temperature and Time Dependence on the Degree of Acid Defluorination

Their average sizes are 54.2 and 52.6 microns, respectively. the dependence of the growth of sodium silicofluoride crystals on the temperature of the defluorination process for 10,30 and 60 minutes are shown in Fig.-1, which shows that the maximum on the curves corresponds to a temperature of $40-50^{\circ} \mathrm{C}$. At the same time, the sizes are 45 microns in $10 \mathrm{~min}, 53-54$ microns in $30 \mathrm{~min}$, and 35 microns in 60 min. ${ }^{7,9}$ It should be noted that the crystals mainly fall in the form of drusy aggregates.It is believed that druses are formed either with very slow crystallization, or with very slow mixing, or with constrained crystal growth when they come into contact with the bottom or walls of the apparatus, the faces of several growing crystals, the presence of impurities in the solution, etc. ${ }^{10}$ The formation and appearance of drusus crystals are mainly determined by the shape of the crystal nuclei, the surface on which they grow, and the interaction of several growing crystals. In our studies, we assume that the formation of drusas is affected by the process of slow mixing and the presence of impurities in the acid. Increasing the temperature to 60$70^{\circ} \mathrm{C}$ also shows a significant effect on the size of crystals, which are much smaller at these temperatures. ${ }^{11}$ The growth of $\mathrm{Na}_{2} \mathrm{SiF}_{6}$ crystals is also affected by the mixing time after the introduction of the precipitator. In the initial period, when the mixing time increases from 10 to 30 minutes, the crystals grow with the drop-out in the form of drusas. ${ }^{8,11}$ Longer mixing, for 45-60 minutes, leads to the collision 
RASĀYAN J. Chem.

Vol. 14 | No. 4 |2273-2278| October- December | 2021

of crystals, the destruction of their joints and the displacement of the average dimensions of crystals for example, at $40^{\circ} \mathrm{C}$ for a time of $10-30 \mathrm{~min}$, the average size of crystals reaches up to 54 microns and then decreases and amounts to 34 microns with an increase in time to 60 minutes.

Precipitation of sodium silicofluoride from WPA with aqueous solutions of sodium salts was carried out depending on the norm of the precipitator, the flow rate varying from 100 to $200 \%$ of the stoichiometry. ${ }^{12}$ The process of defluorination was carried out at a temperature of $40^{\circ} \mathrm{C}$ and a time of 30 minutes, with a slow introduction of an aqueous solution of sodium salts heated to the temperature of the experiment. the concentration of the solution was about $9 \% \mathrm{Na}_{2} \mathrm{O}(6.7 \% \mathrm{Na})$ and $0.35 \% \mathrm{~K}_{2} \mathrm{O}(0.29 \% \mathrm{~K})$ (Table-2).

Table-2: The Influence of the Norms of Sodium Salts on the Degree of Defluorination WPA

\begin{tabular}{c|c|c|c|c|c|c}
\hline $\begin{array}{c}\text { Consumption } \\
\text { Rate of Sodium } \\
\text { Salts, } \%\end{array}$ & $\begin{array}{c}\text { Number of } \\
\text { inputs }\end{array}$ & \multirow{2}{*}{$\begin{array}{c}\text { Defluorination } \\
\text { Degree, \% }\end{array}$} & \multicolumn{3}{|c|}{ Content in WPA, \% } & \multirow{2}{*}{$\begin{array}{c}\text { Crystal Size, } \\
\text { microns }\end{array}$} \\
\hline 100 & 0.57 & 62.5 & 0.61 & 0.623 & 0.098 & 15.8 \\
\hline 120 & 0.68 & 80.2 & 0.32 & 0.662 & 0.195 & 40.0 \\
\hline 140 & 0.80 & 86.0 & 0.23 & 0.771 & 0.221 & 52.5 \\
\hline 160 & 0.91 & 87.0 & 0.21 & 0.932 & 0.232 & 50.7 \\
\hline 200 & 1.04 & 88.6 & 0.22 & 1.241 & 0.320 & 41.3 \\
\hline
\end{tabular}

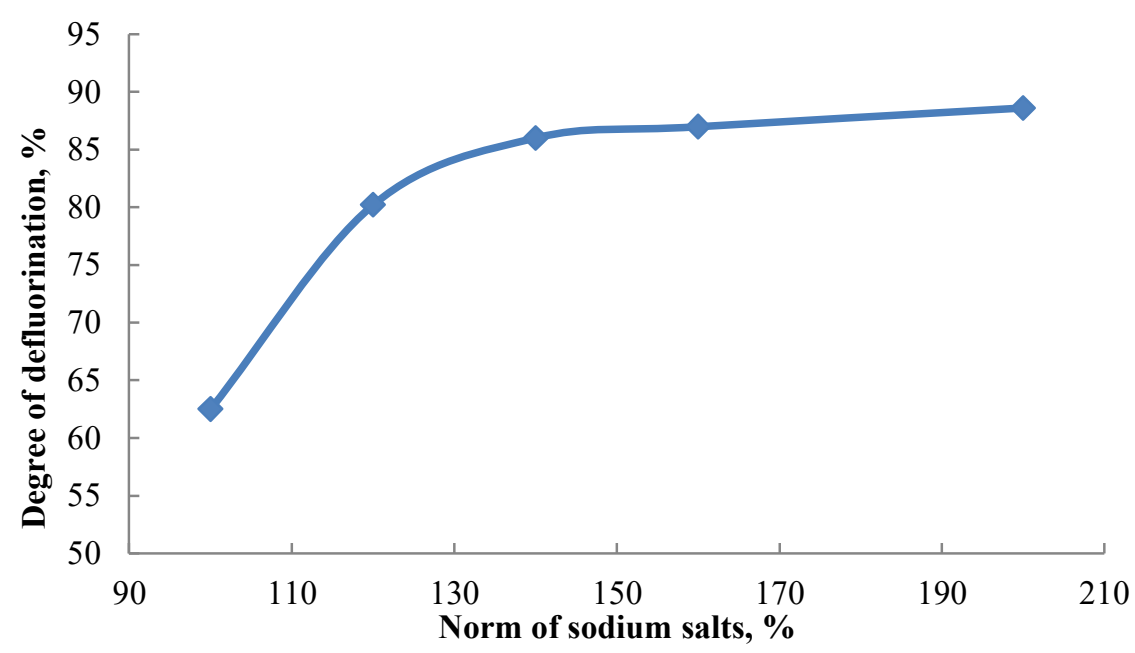

Fig.-2: Dependence of the Norm of Sodium Salts on the Degree of Acid Defluorination

Analysis of Table-2 and Fig. -2 shows that the residual F content in the acid decreases from 0.6 to $0.2 \%$, while the degree of defluorination increases from 63 to $88.6 \%$, respectively.

It should be noted that a significant increase in the degree of defluorination is observed when the rate of consumption of the precipitator increases from 100 to $140 \%$. A further increase in the amount of precipitator to $200 \%$ increases the degree of desulfurization by only $2.6 \%$.

The results of wavemetric observations of the precipitating crystals of sodium silicofluoride showed that they fall out in the form of crystals of isometric, hexagonal shapes. At a $100 \%$ precipitation rate, crystals fall out, with an average size of $15.6 \%{ }^{13}$ starting from the sedimentation rate of $120 \%$ of the stoichiometry, $\mathrm{Na}_{2} \mathrm{SiF}_{6}$ crystals precipitate as aggregates of drusus crystals consisting of seven separate crystals. ${ }^{14}$ At a rate of $\mathrm{Na}_{2} \mathrm{O}-120 \%$, the size of some grains reaches 52.5 microns, and the size of individual crystals of sodium silicofluorides under these conditions was 40.0 microns. Further increase in the sedimentation rate from 140 to $160 \%$ of the stoichiometry average crystal sizes increase to 50 51 micron and druses of size $78-88$ micron are found.

It should be noted that, with a flow rate of $160 \%$ of stoichiometry, the size of drusas and their number are slightly increased than with other standards. However, the number of small crystals (16microns) at a rate of $160 \%$ is also higher than at a rate of $140 \%$ of the precipitator from stoichiometry. ${ }^{6,13}$ Further 
supersaturation of the solution with sodium salts (up to 200\%) from stoichiometry, the average size of sodium silicofluoride crystals is up to 41.3 microns, i.e. the greater the supersaturation of the solution, the smaller the size of the resulting $\mathrm{Na}_{2} \mathrm{SiF}_{6}$ crystals. ${ }^{15}$

Analysis of tabular data shows that to obtain the largest crystals of sodium silicofluoride, the excess of the precipitator should be $20-40 \%$ more than the stoichiometric amount, which is the degree of defluorination, about $86 \%$ and the residual content of fluorine in the acid is not more than $0.23 \% .{ }^{16}$

When a sodium-containing solution is introduced in an amount of $140 \%$ of the stoichiometry, the acid is diluted to a $\mathrm{P}_{2} \mathrm{O}_{5}$ content of about $19.05 \%$, with a reduced concentration of $2.0-2.5 \%$.

Consequently, with an increase in the amount of introduced liquor, there is an increase in the content of sodium and potassium ions in the defluorinated acid. ${ }^{17,18}$

A sufficiently high degree of defluorination is achieved at the lowest cost of the precipitator and the rate of consumption of sodium salt solutions is $140 \%$ of the stoichiometry. ${ }^{18}$ This norm corresponds to the largest sizes of crystals falling out of sodium silicofluorides. At the same time, defluorinated extraction phosphoric acid has the following composition: $\mathrm{P}_{2} \mathrm{O}_{5}-19.34 ; \mathrm{F}-0.23 ; \mathrm{Na}_{2} \mathrm{O}-0.77 ; \mathrm{K}_{2} \mathrm{O}-0.27$

\section{CONCLUSION}

Results of studies show reduce the precipitator flow rate from the time and temperature of the process. An increase in the temperature of the process from 25 to $70^{\circ} \mathrm{C}$ reduces the degree of acid drying by sodium salt solutions $\left(6.75-\mathrm{Na}_{2} \mathrm{O}\right)$ at a precipitator ratio of $140 \%$ from $84 \%$ to $74 \%$. Mixing times and process temperatures have a significant influence on the size of the precipitating $\mathrm{Na}_{2} \mathrm{SiF}_{6}$ crystals. The crystals reach the largest size at a mixing time of $30 \mathrm{~min}$ and a temperature of $40-50^{\circ} \mathrm{C}$ and are 54 microns, the $\mathrm{Na}_{2} \mathrm{O}$ norm is $140 \%$ of the solution concentration of $6.75 \% \mathrm{Na}_{2} \mathrm{O}$. In terms of the maximum degree of acid defluorination by aqueous solutions of sodium salts and to produce the largest, well filtered $\mathrm{Na}_{2} \mathrm{SiF}_{6}$ crystals with as little phosphoric acid dilution as possible with sodium salts should be considered in our view the following conditions for fluorine deposition: normal precipitator (solution) $120-140 \%$ of the stoichiometric solution concentration of $6.75 \% \mathrm{Na}_{2} \mathrm{O}$, the temperature of $40-50{ }^{\circ} \mathrm{C}$, duration of sedimentation - 30min. Under these conditions, the composition of defluorinated phosphoric acid: $\mathrm{P}_{2} \mathrm{O}_{5}-$ $19 \%$ : P- $-2.24 \%$ and the size of the crystals of sodium silicofluoride was 50-40 micron.

\section{REFERENCES}

1. R. Al Rawashdeh and P. Maxwell, Mineral Economics, 24, 15(2011), https://doi.org/10.1007/s13563011-0003-8

2. S.Schultheiss, I.Sethmann, M.Schlosser and H.-J.Kleebe, Mineralogical Magazine, 77, 2725(2018), https://doi.org/10.1180/minmag.2013.077.6.03

3. P. Becker, Phosphates and Phosphoric Acid, Raw Materials, Technology, and Economics of the Wet Process, 2nd edn., Marcel Dekker, Inc., New York, USA, p.253 (1989).

4. O. E. Gorlova, I. V. Shadrunova and O. M. Sinjanskaja, Gornyjinformacionno-analiticheskijbjulleten' (nauchno-tehnicheskijzhurnal) - Mining Information and Analytical Bulletin (Scientific and Technical Journal), 12, 157(2018)[in Russian].

5. G. T. Austin, Shrieve's Chemical Process Industries, McGraw Hill, New York, USA, p.150 (1984).

6. M. Chen and T. E. Graedel, Global Environmental Change, 36, 139(2016), https://doi.org/10.1016/j.gloenvcha.2015.12.005

7. T. S. Bazhirov, K. T. Zhantasov and O. B. Dormeshkin, Theoretical Foundations of Chemical Engineering, 49, 277(2015), https://doi.org/10.1134/S004057951503001X

8. A. Ja. Syrchenkov, Z. A.Tihonovich, I. G. Grishaev, A.A.Korshuk and N.V.Sobolev, Trudy NIUIF Proceedings of NIUIF, pp. 389-394(2004)[In Russian].

9. B. G. Michael, R. Pablo, J. T. Wesley and C. C. Christopher, Journal of American Chemical Society, 141(15),6375(2019).

10. K.T. Zhantasov, S. Sh. Shalataev, A. A. Kadirbayeva, D. M. Zhantasova, Zh. K. Dzhanmuldaeva, B. Ismailov and I. A. Petropavlovsky, Oriental Journal of Chemistry, 33(3), 1381(2017).

11. K. T. Zhantasov, S.M. Moldabekov, A.A. Kadirbaeva, M.I. Nalibaev, D.M. Zhantasova, T.Alteev, M.K. Zhantasov, A.Z. Zijat and K.N. Bazhirova, Uspehisovremennogoestestvoznanija - Advances in Modern Natural Science, 12, 405(2014)[in Russian]. 
RASĀYAN J. Chem.

Vol. 14 | No. 4 |2273-2278| October- December | 2021

12. K.T. Zhantasov, Zh.U. Myrkhalykov,Sh. Moldabekov and M.M. Yeskendirova, Eurasian ChemicoTechnological Journal, 17(1), 79(2015).

13. G. H. Wesenberg, Diammonium Phosphate Plantes and Processed, Manual of Fertilizer Processing, Basel, New York, USA, p.87 (1987).

14. R. Loste and J. L. Toral, In Proceeding of International Conference Fertilizer, London, UK, pp.197204 (1983).

15. Development in the Cross Fertilizer Process Improved Efficiency, Lower Operating Costs and Higher Capacity, Phosphorus and Potassium, 100, 25(1979).

16. Granular Fertilizer Production, The Espindesa/ERT Pipe Reactor Process, Phosphorus and Potassium, 405, 28(1980).

17. K. T. Zhantasov, Technologies of Extraction and Enrichment of Phosphate-siliceous Raw Materials of Karatau, Monography, Taraz, Kazakhstan, p. 174 (2018) [in Russian].

18. J. D. Crerar, J. D. C. Hemsley, I. C. Hepworth, US Patent 3974263 (1976).

[RJC-6472/2021] 